\title{
Rotational pericardial flap: An alternative tension-free technique for pericardial closure
}

\author{
Faranak Kargar, MD, and Mathias H. Aazami, MD, Tehran, Iran
}

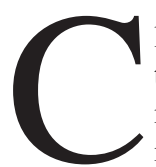

losing the pericardium in patients with preserved ventricular function has been proposed as a protective measure attempting to minimize the hazards of injuring the myocardium, coronary grafts, and great vessels at the time of reoperation. ${ }^{1}$ Despite its own set of advantages, in view of the increasing number of cardiac reoperations, classical pericardial closure has not gained increasing acceptance, mainly because of concerns over its attendant adverse hemodynamic effects. $^{2,3}$ In the interim, using alternative techniques deemed as tension-free pericardial closure or pericardial substitutes has been advocated to benefit patients with safer resternotomy while minimizing the adverse effects on immediate postoperative hemodynamics. ${ }^{4,5}$ Following this line of reasoning, we report an alternative technique for tension-free pericardial closure that results in layering the right ventricular free wall and infundibulum by means of a rotational pericardial flap while leaving the great vessels unlayered, thereby minimizing the likelihood of compressive effects on the great vessels and top-end anastomosis.

\section{Clinical Summary}

After median sternotomy, the prepericardial fat, pleural reflections, and thymic remnants are gently dissected away. The pericardium is entered horizontally $1 \mathrm{~cm}$ below its anterosuperior reflection (Figure 1, A). The incision is continued downward along the left side, keeping away from the left phrenic pedicle. The inferior margin of the flap is constructed by reflecting the incision horizontally to the right, keeping $1 \mathrm{~cm}$ away from the diaphragmatic margin. The flap is completed by extending the superior incision along the right pericardial border, which further facilitates rotating the flap.

At the end of the cardiac procedure, an intrapericardial drainage tube is inserted properly, and the flap is laid over the right ventricular free wall and infundibulum by rotating the flap inferiorly toward the apex; the flap is then secured in place to the left and diaphragmatic pericardial margins by using separate stitches (Figures 1). By using this maneuver, the pulmonary artery, aorta,

\footnotetext{
From the Iran University of Medical Sciences, Rajaei Heart Center, Cardiac Surgery Department, Tehran, Iran.

Received for publication March 29, 2007; accepted for publication April 20, 2007.

Address for reprints: Mathias Aazami, MD, Cardiac Surgery Department, Rejaei Heart Center, Melat Park, Tehran, Iran (E-mail: mathias.aazami@ laposte.net).

J Thorac Cardiovasc Surg 2007;134:510-1

$0022-5223 / \$ 32.00$

Copyright @ 2007 by The American Association for Thoracic Surgery doi:10.1016/j.jtcvs.2007.04.006
}

superior vena cava, and top-end anastomosis are unlayered, which can be covered in turn by approximating the thymic remnants.

Since December 2005, this new approach has been used in 74 elective patients (mean age, $52 \pm 21$ years; ejection fraction, $44 \% \pm$ $57 \%$ ) with various surgical indications (Table 1). In the group undergoing coronary artery bypass grafting, the left internal thoracic artery was used systematically to bypass the left anterior descending artery. The ostium secundum was closed with fabric material. There was 1 operative death caused by perioperative stroke; no major complications occurred among survivors, especially not documented perioperative ischemia or low cardiac output episode. All patients were extubated within 24 hours after the operation except 1 . There was no reoperation because of postoperative bleeding or tamponade, and postpericardiotomy syndrome did not occur. Transthoracic echocardiography was performed at the time of discharge; greater than trivial pericardial effusion was not evidenced in any patient. One patient previously operated on for mitral valve replacement underwent reoperation 1 month later for massive pericardial effusion associated with warfarin overdose.

\section{Discussion}

In a clinical trial attempted to study the geometric effects of primary closure of the native pericardium (PCNP), Rao and colleagues ${ }^{1}$ found a significantly greater retrosternal distance between the epicardium and the posterior sternal table when PCNP was carried out. Therefore, PNPC might afford protection for the right ventricle and overlying bypass grafts if repeat sternotomy is necessary, and it should be recommended when possible. .,4,5 $^{1,4}$

However, an increased risk of postoperative cardiac tamponade and adverse short-term hemodynamic consequences of pericardial closure on cardiac function sustain slower progress toward incorporating PCNP into the routine practice. ${ }^{1-3}$ Compounding the available experimental and clinical data is the fact that the compressive effects of PCNP, given increasing ventricular filling pres-

\section{TABLE 1. Operative indications}

\begin{tabular}{lc}
\hline Procedure & No. \\
\hline CABG & 43 (3.56 grafts per patient) \\
AVR & 1 \\
AVR + CABG & 1 \\
MVR & 14 \\
MVR + TVR/TV repair & 2 \\
MVR + ASD closure & 2 \\
TVR & 3 \\
ASD & 8
\end{tabular}

$C A B G$, Coronary artery bypass grafting; $A V R$, aortic valve replacement; $M V R$, mitral valve replacement; $T V R$, tricuspid valve replacement; $T V$, tricuspid valve; $A S D$, atrial septal defect. 

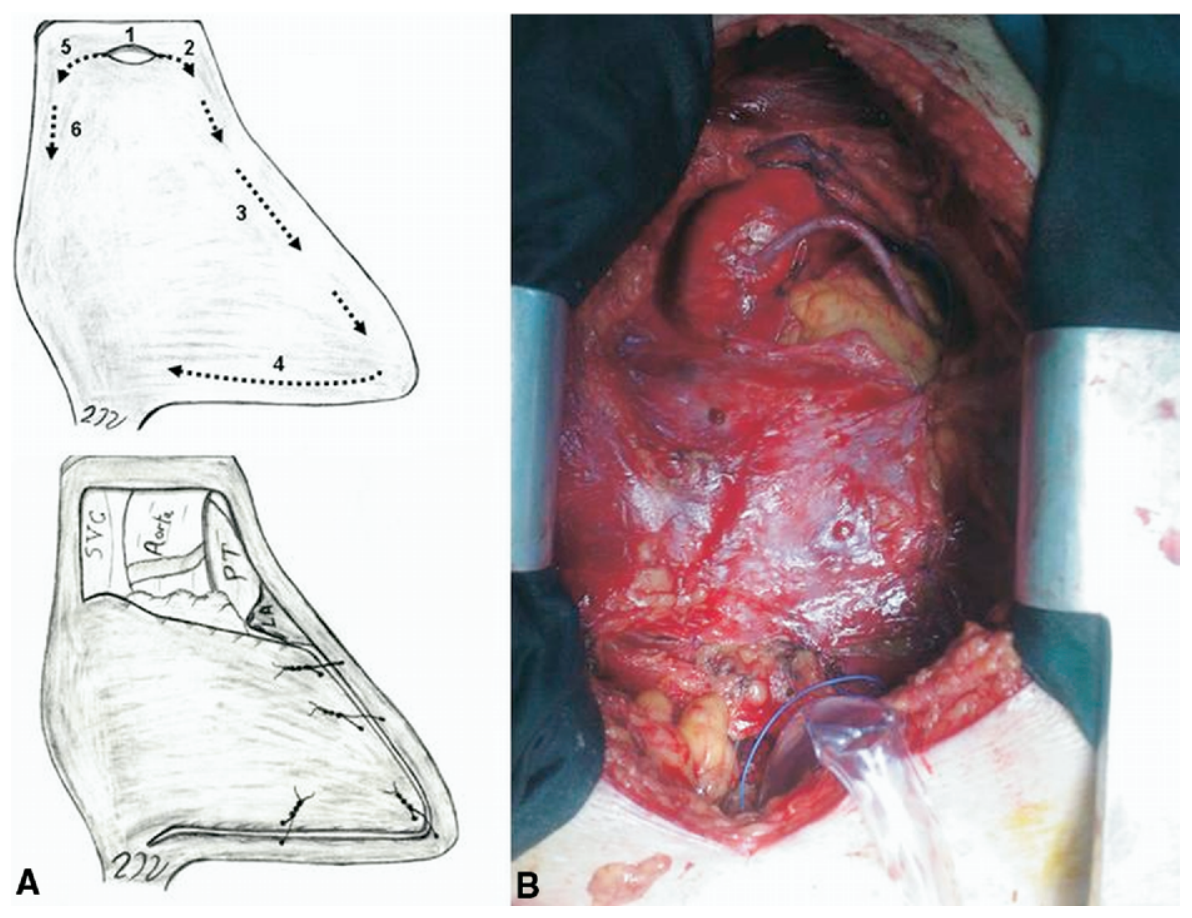

Figure 1. A, Drawings show the sequence of the pericardial incision lines (top) and the final result after completion of pericardial closure with a rotational pericardial flap (bottom). B, Operative image. The top-end anastomosis and supracardiac vessels are not layered, which in turn can be covered by approximating the thymic remnants.

sures, might partly be exerted at the supracardiac level on the main pulmonary artery and superior vena cava, resulting in both right ventricular increased afterload and reduced preload., ${ }^{2,4,5}$ When it comes to circumventing the adverse hemodynamic effects, alternative closing techniques, deemed as tension-free pericardial closure, have been developed that address, to some extent, pericardial contraction and lessen its resultant compressive effects. ${ }^{1,4,5}$

In our series the rotational pericardial flap as an alternative tension-free technique for pericardial closure has proved to be safe and reproducible in patients with preserved systolic ventricular function. It offers a distinct advantage in restoring the pericardial continuity at the ventricular level while leaving unlayered the supracardiac vessels and top-end anastomosis, which is aimed at reducing the compressive effects. Nevertheless, its protective effect at the time of resternotomy needs to be further investigated.

\section{References}

1. Rao V, Komeda M, Weisel RD, Cohen G, Borger MA, David TE. Should the pericardium be closed routinely after heart operations? Ann Thorac Surg. 1999;67:484-8.

2. Daughters GT, Frist WH. Effects of the pericardium on the left ventricular diastolic and systolic performance early after cardiac operations. J Thorac Cardiovasc Surg. 1992;104:1084-91.

3. Hunter S, Smith GH, Angelini GD. Adverse hemodynamic effects of pericardial closure soon after open heart operation. Ann Thorac Surg. 1992;53:425-9.

4. Milgalter E, Uretzky G, Siberman S, Appelbaum Y, Shimon DV, Kopolovic J, et al. Pericardial meshing: an effective method for prevention of pericardial adhesions and epicardial reaction after cardiac operations. J Thorac Cardiovasc Surg. 1985;90:281-6.

5. Izzat MB, Anderson M, Wilde P, Wisheart JD, Bryan AJ, Angelini GD. Hemodynamic effects and echocardiographic consequences of tensionfree pericardial closure after heart valve surgery. $J$ Heart Valve Dis. 1994;3:295-9. 